\title{
Recent advances in the physiology of eating
}

\author{
Stephen French ${ }^{1 *}$ and Kate Castiglione ${ }^{2}$ \\ ${ }^{1}$ Masterfoods (a division of Mars UK Ltd), Dundee Road, Slough SL1 4JX, UK \\ ${ }^{2}$ Centre for Human Nutrition, University of Sheffield, Northern General Hospital, Herries Road, \\ Sheffield S5 7AU, UK
}

\begin{abstract}
Since the discovery of the protein product of the $o b / o b$ gene, leptin, knowledge of the neurochemical pathways involved in the regulation of feeding has increased enormously. Our understanding of the mechanisms regulating food intake in man has also progressed greatly over a similar time span. Previous research into the regulation of food intake has largely proceeded through a reductionist approach, defining ever-smaller components of these mechanisms. This research strategy has been very productive and instructive, and has yielded a great deal of information on the specific putative components linking energy status and food intake. However, to fully understand the regulation of feeding it is important that these components are systematically reconstructed to investigate relevant interactions. In the present review recent data relating to interactions between systems proposed to be involved in feeding regulation will be highlighted. The review will be directed predominantly (but not exclusively) towards the regulation of human feeding.
\end{abstract}

Feeding behaviour: Physiology of eating: Man

The understanding of the physiological regulation of food intake has advanced rapidly through the development of new and more refined techniques of measurement. This advance has led to a greater understanding of the genetic, molecular, hormonal, neural and behavioural mechanisms underlying the regulation of energy balance. It is not within the scope of the present review to consider all aspects of these factors, and many reviews have been written recently in these areas (for example, see Beck, 2000; de Castro, 2000; Moran, 2000; Plata-Salaman, 2000). In the present review we will focus on the techniques that have specifically impacted on our understanding of the processes of eating, i.e. what causes us to eat, what stops us eating and what we know about the integration of signals that inform the body of current status. While not exclusively, the present review will also focus primarily on the understanding of human feeding.

Since the classic studies identifying the hypothalamus as a major area of control of feeding (Anand \& Brobeck, 1951; for summary, see Jequier \& Tappy, 1999), much of the research to elucidate mechanisms associated with feeding control has been conducted through a reductionist approach. The physiological systems have been dissected by increasingly more refined methodologies to allow us to investigate the roles of organs, signalling mechanisms, genes and neurons in the control of feeding. This process has been necessary in order to gain an understanding of the importance of these specific factors in the control of feeding. However, this approach does not reflect how we feed normally; animals process information from many sources simultaneously and show a great deal of redundancy in the processing of information. Hence, there is now a necessity to reconstruct systems of regulation in order to understand the complex nature of interplay of factors involved in feeding control.

\section{Human feeding}

Advances in the physiology of human feeding have stemmed from two major routes. First, the role of organ function has been investigated by studying how food intake is affected by pharmacological agents available for human use, and improvements in the techniques available for direct measurement and manipulation of organ function. Second, advances in the techniques of measurement of the feeding process itself have led to a better understanding of the underlying factors involved in this regulation and of the impact of external factors (e.g. diet composition) on this 
regulation. The present review will aim to cover each of these factors in turn.

\section{Role of specific organs in feeding control}

\section{Gastric capacity}

Measurement of the capacity of the human stomach by inflation of an intragastric balloon has yielded interesting findings concerning its relationship with satiety. Gastric capacity has been demonstrated to be correlated with test meal intake, suggesting that a stomach with a large capacity may require a larger meal to induce satiety. Furthermore, a stomach with a larger capacity may empty liquid meals more slowly, thus delaying the release of the putative satiety hormone cholecystokinin (CCK) and reducing satiety (Geliebter et al. 1992). It had been reported previously that the stomach capacity was larger in obese individuals than in normal-weight individuals (Granstrom \& Backman, 1985; Geliebter, 1988). A recent study, measuring gastric capacity in normal, obese and bulimic subjects, found the greatest gastric capacity in bulimic subjects, an intermediate capacity in obese subjects and the smallest capacity in normal subjects (Geliebter \& Hashim, 2001). When the authors subdivided the obese group into binge-eating and non-binge-eating individuals, the binge-eating individuals were shown to have a capacity similar to that of bulimic subjects, while the capacity of non-binge-eating subjects was similar to that of normal subjects. Thus, volume of food consumed seems more relevant in predicting gastric capacity than obesity per se, suggesting that the biological capacity of the stomach may control and limit food intake. Interestingly, obese subjects who were asked to undertake an energy-restricted $(2510 \mathrm{~kJ}(600 \mathrm{kcal})$ formula/d) diet for 4 weeks were found to have a reduced stomach capacity following the diet compared with that before the diet (Geliebter et al. 1996), indicating that these anatomical changes are reversible.

\section{Gastrointestinal tract}

We and other researchers have investigated the role of specific organ systems in the regulation of human feeding. While these techniques are not new, recent improvements in methodology have meant that it is now possible to conduct relatively invasive procedures in human volunteers, while causing the minimum of distress to the individual (an imperative if any inference on normal behaviour is to be made). Infusions of nutrients into specific areas of the gastrointestinal tract can be made relatively quickly and with good precision. For example, using $\mathrm{pH}$ probes or measurement of potential difference it is now possible to monitor the position of the tip of the infusion probe and determine its passage from the stomach to the small intestine without the requirement for radiographic screening of the abdomen. In most cases it is now possible to site an infusion tube in the upper small intestine within 30-45 min of nasogastric insertion (French et al. 1997; Castiglione et al. 1998). Similarly the use of computer-controlled barostats allows accurate distension of the stomach to be performed to either fixed volumes or pressures (Francis et al. 1997).
These advances make within-subject comparisons using complicated experimental designs possible and tolerable to subjects.

Combining manometric techniques with infusion techniques has increased our understanding of the interaction of signalling between the stomach and small intestine. Feinle et al. (1997) showed that while distension of an inflatable bag within the stomach of volunteers led unsurprisingly to feelings of epigastric pressure, combination of this procedure with nutrient infusion into the upper small intestine changed the quality of the feelings to a more meallike sensation. Furthermore, this meal-like sensation could be reversed by using a specific antagonist to the gastrointestinal hormone CCK. Good evidence exists for the role of CCK as a mediator of satiety in human subjects, particularly in conjunction with other short-term satiety mechanisms (for review, see Degen et al. 2001).

Several other gastrointestinal peptides have been proposed to act as mediators of satiety in animals, although relatively few of these peptides have been rigorously tested in human subjects. Currently, the second-most-likely candidate for a physiological stimulus for satiety in human subjects is glucagon-like peptide 1. This peptide is expressed and released from the distal small intestine in response to the presence of unabsorbed nutrients in the lumen or in response to the absorptive process itself (Holst, 1994).

\section{Adaptation of gastrointestinal responses}

Evidence from studies in animals and human subjects suggest that consumption of a high-fat diet (HFD) leads to changes in small intestinal responses associated with the control of feeding. These changes could lead to increased intake, absorption and storage of dietary fat and, therefore, predispose to weight gain and the development of obesity. Adapting rats to an HFD reduces the inhibition of gastric emptying induced by intraperitoneal injection of CCK and by intraduodenal infusion of oleate (Covasa \& Ritter, 2000). In the same study the HFD had no effect on the inhibition of gastric emptying in response to intraduodenal infusion of the oligosaccharide maltotriose compared with rats fed a low-fat diet, suggesting that HFD may lead to adaptations that are nutrient specific. Changes in gastric emptying and meal transit times have also been observed in human subjects. Consumption of an HFD for 2 weeks produced an increase in the half-emptying time and mouth-to-caecum transit time of a fatty test meal in comparison with after consumption of a low-fat diet (Cunningham et al. 1991). Futhermore, adaptive changes in gastric emptying that are specific to fat have also been observed recently in human subjects (Castiglione et al. 2002). Consumption of an HFD for 2 weeks produced an acceleration of gastric emptying during the linear phase of emptying of a high-fat test meal, but not of a high-carbohydrate test meal. Preliminary data for human subjects suggests that this fat-specific change in gastric emptying is not due to a change in CCK receptor sensitivity ( $\mathrm{K}$ Castiglione and $\mathrm{S}$ French, unpublished results). Measurement of plasma CCK levels and gallbladder emptying during a controlled intestinal infusion of fat before, during and after an HFD showed a trend towards 
an attenuation of the plasma CCK response following the HFD, with no accompanying change in gall-bladder emptying.

High-fat feeding has also been shown to produce changes in satiety, as measured by food intake and ratings of satiety. Rats maintained on an HFD show a reduction in the ability of intestinal oleate infusions to reduce food intake (Covasa \& Ritter, 1999) and reduced sensitivity to the satiating effects of CCK and bombesin injections (Covasa \& Ritter, 1998). In human subjects consumption of an HFD for 2 weeks led to increased food intake, as measured by food diaries, and trends towards increasing feelings of hunger and decreasing fullness over the 2-week diet period (French et al. 1995).

\section{Nutrient metabolism and satiety}

Preliminary data from human subjects suggest that there may be an interaction between either the state of nutrient stores or the metabolic fate of nutrients and gastrointestinal signals in the regulation of feeding. We have previously observed increases in short-term feeding in human subjects following exercise regimens designed to deplete carbohydrate stores (Lavin et al. 1997). Furthermore, unpublished results (SJ French, KL Yip, JH Lavin and NW Read) suggest that following a fixed preload subjects who had previously undergone glycogen-depleting exercise do not reduce their feeding initially as much as when the same exercise is combined with glycogen-sparing drinks. These data therefore suggest that the gastrointestinal signals stimulated by the preload may be desensitised by glycogen-depleting exercise.

Further evidence that gastrointestinal signals interact with metabolic signals in the control of feeding comes from studies in human subjects utilising glucose and insulin clamps. Increases in blood glucose within the physiological postprandial range $(8-11 \mathrm{nmol} / \mathrm{l})$ have been shown to slow gastric emptying (Schvarcz et al. 1997), while hypoglycaemia accelerates gastric emptying rate in both healthy patients and patients with insulin-dependent diabetes mellitus (Schvarcz et al. 1993, 1995). Investigation of the effects of modest changes in blood glucose levels within the physiological range also found differences in appetite responses between blood glucose levels of 5 and $8 \mathrm{mmol} / \mathrm{l}$ (Andrews et al. 1998). There was no difference in rated hunger in the fasted state between blood glucose levels of 5 and $8 \mathrm{mmol} / \mathrm{l}$; however, fullness was greater at $8 \mathrm{mmol} / \mathrm{l}$. During intraduodenal lipid infusion, however, ratings of hunger, desire to eat and projected consumption were all reduced at a blood glucose level of $8 \mathrm{nmol} / \mathrm{l}$ compared with $5 \mathrm{mmol} / \mathrm{l}$, supporting synergy between blood glucose concentration and stimulation of small intestinal nutrient receptors in regulating appetite. Other glucose-clamping studies, however, have shown interaction between different levels of blood glucose and the satiating efficiency of CCK in the opposite direction (Lam et al. 1998). During normoglycaemic conditions appetite, as measured by wish-to-eat and hunger ratings, was decreased by intraduodenal fat infusion and by intravenous CCK infusion. In contrast, during hyperglycaemia $(15 \mathrm{mmol} / \mathrm{l})$ a significant increase in appetite was observed in response to intraduodenal fat and
$\mathrm{CCK}$ infusion. The authors proposed that the reduced satiety effect of CCK was due to the blockade by hyperglycaemia of vagal-cholinergic afferent nerve fibres, which are involved in the satiety effect of CCK. Previous findings suggest that hyperglycaemia results in reduced firing of the vagal-cholinergic system resulting in 'medical vagotomy' (Oster-Jorgensen et al. 1992). Since hyperglycaemia in turn produces hyperinsulinaemia, it is also possible that the increase in appetite was mediated by an acute rise in plasma insulin.

\section{Hepatic nutrient metabolism and control of feeding}

Russek (1963, 1970) elegantly showed that hepatic nutrient metabolism was important in the normal regulation of feeding in animals. This finding has been subsequently confirmed and refined by several investigators, and it now appears that a common pathway leading from nutrient metabolism to ATP production and cell membrane polarity changes may be involved in the signalling mechanism (Langhans, 1996; Friedman, 1997). Measurement of liver function and manipulation of hepatic nutrient metabolism is difficult in human subjects. Thus, direct manipulation, as has been possible in the gastrointestinal tract, has not been possible for investigating hepatic control of feeding in human subjects. Hence, study of hepatic feeding control has largely relied on pharmacological manipulation of hepatic function and indirect measurement of hepatic function during stages of feeding.

Hepatic oxidation of fatty acids is considered to play a role in the medium- and long-term control of food intake. This hypothesis is primarily based on studies in rats demonstrating that: (1) a pharmacological inhibition of fatty acid oxidation is associated with enhanced feeding; (2) this effect is critically dependent on hepatic vagal afferent nerve fibres (see Langhans, 1996). Recently, the oral anti-diabetic drug etomoxir, which inhibits the oxidation of long-chain fatty acids, has been shown to stimulate eating in human subjects (Kahler et al. 1999), at least in subjects whose dietary fat intake is high, and when baseline hepatic fatty acid oxidation is sufficiently inhibited. By providing the first direct evidence for a role of hepatic fatty acid oxidation in man, these results extend previous findings, which indirectly suggested that hepatic fatty acid oxidation affects food intake in human subjects (Rolls et al. 1988; Stubbs \& Harbron, 1996). In these studies ingestion of medium-chain triacylglycerols, which are rapidly oxidised in the liver, generally reduced food intake. Additional evidence that hepatic fatty acid oxidation has a feeding-suppressive effect in rats is derived from recent findings of an inhibition of feeding in response to sustained oleate infusion via the hepatic portal vein, which was absent after hepatic branch vagotomy (L Benthem and W Langhans, unpublished results).

Recently, we have investigated the role of hepatic fatty acid metabolism in human subjects using L-carnitine (AS Rinomhota, CA Beck, S Walters, W Langhans, RJM Ross and SJ French, unpublished results). Carnitine promotes fatty acyl-CoA transport across inner mitochondrial membranes (Eaton, 2002). Thus, under conditions of high substrate availability carnitine can increase fatty acid 
utilisation. Hence, in order to maximise circulating fatty acid substrate, subjects were also required to perform lowintensity exercise for $1 \mathrm{~h}$ on the day of the study and consume a low-energy HFD for the day before the study, in addition to a carnitine or placebo capsule. Despite increases in plasma $\beta$-hydroxybutyrate concentration, indicating an increase in hepatic fatty acid oxidation, carnitine supplementation at two doses $(1.5$ and $3.0 \mathrm{~g})$ had no overall effect on food intake. Thus, although inhibition of fatty acid oxidation stimulates food intake, increasing fatty acid oxidation, particularly in human subjects, does not appear to consistently reduce appetite or food intake.

Hydroxycitrate (HCA), a compound derived from the rind of the fruit Garcinia cambogia, has been promoted as a weight-loss agent. HCA inhibits ATP-citrate-lyase, an enzyme that catalyses the cleavage of citrate to acetyl-CoA and oxaloacetate (Watson et al. 1969), which is a key step in de novo lipogenesis. Thus, HCA might prevent weight gain by inhibiting lipogenesis. In addition, HCA-associated weight loss may be produced through increased satiety by increasing fat oxidation. The effects of HCA on appetite, feeding, weight loss and energy expenditure have been measured in both animals and human subjects. In animals most studies have demonstrated reduced food intake and reduced body weight with HCA administration. In rats HCA reduced body weight by suppressing food intake, and possibly also due to increased energy expenditure, after a period of restrictive feeding. The suppression of food intake by HCA was particularly strong with a high-glucose HFD, but was not seen with chow (Leonhardt et al. 2001). In human subjects, however, there are conflicting reports on the weight-reducing effects of HCA. Some studies have shown a positive effect of HCA on body-weight loss but not on appetite, energy intake or energy expenditure, while other studies have failed to observe any effect. HCA supplementation for 2 weeks had no effect on satiety, energy intake, body-weight loss, fat oxidation or $24 \mathrm{~h}$ energy expenditure of subjects losing body weight (Kovacs et al. $2001 a, b)$. In a larger study ( $n$ 89) of participants on a weight-reducing diet a greater loss of body weight was observed in the group receiving $\mathrm{HCA}$, despite finding no effects on rated measures of appetite (Mattes \& Bormann, 2000).

\section{Continuous glucose monitoring}

Computer-based technology for the continuous measurement of blood glucose has previously been used in rats allowed to feed ad libitum to demonstrate that transient declines in blood glucose are causally related to, and signal, meal initiation under free-living conditions (for example, see Campfield \& Smith, 1986; Smith \& Campfield, 1993). Studies investigating the role of blood glucose in meal initiation and hunger in human subjects were previously limited by the need for an investigator to take discrete blood samples on a fixed schedule. Campfield et al. (1996) have recently adapted these remote techniques to allow continuous monitoring of blood glucose levels in human subjects. The method utilises a long double-lumen catheter placed in an antecubital arm vein, which still allows the participant to rest, sleep, read or write during monitoring.
When blood glucose levels were measured over a 2-6h period in participants who were isolated from food and hunger cues, changes in hunger and meal requests were preceded by, and correlated with, brief transient declines in blood glucose in $83 \%$ of the participants. The same association between hunger ratings and transient declines in blood glucose was seen when acute insulin infusions $(5 \mathrm{mU} / \mathrm{kg}$ body weight administered over $2 \mathrm{~min}$ ) were used to mimic spontaneous transient declines in blood glucose. Preliminary data ( $n$ 5) showed that no changes in hunger ratings were observed while blood glucose was stable; however, hunger ratings increased after insulin-induced decreases in blood glucose (Campfield et al. 1996). Continuous monitoring of blood glucose levels after isoenergetic isovolumetric highfat or high-carbohydrate preloads in time-blinded subjects also showed an association between transient declines in blood glucose and meal requests; with requests taking twice as long to occur following high-fat preloads compared with high-carbohydrate preloads (Melanson et al. 1999). Thus, the synchronisation of meal requests and dynamic declines in blood glucose have been shown to be related to the reported greater satiating efficiency of high-fat preloads compared with high-carbohydrate preloads in these studies. These findings provide strong evidence that hunger and meal initiation are associated with rapid declines in blood glucose in human subjects, although the mechanisms underlying this association have not been elucidated.

\section{Adiposity signals}

Insulin and leptin are hypothesised to act as 'adiposity signals' to the brain for the long-term regulation of food intake and body weight. Like leptin, circulating concentrations of insulin are proportional to the size of body fat stores (Schwartz et al. 1994; Kaiyala et al. 1995). It is proposed that changes in plasma levels of leptin and insulin are reflected in central concentration changes that indicate a state of altered energy homeostasis and adiposity to the brain to elicit responses to adjust food intake and restore adipose tissue mass to a regulated level (Baskin et al. 1999b).

Leptin appears to have a dual action on the regulation of body weight through the reduction of food intake and stimulation of energy expenditure (Jequier \& Tappy, 1999), although evidence to date in human subjects suggests that the effects are primarily on energy intake (Farooqi et al. 1999). Evidence from animal studies suggests that the weight-reducing effects of leptin are mediated through inhibition of hypothalamic neuropeptide Y release (Stephens et al. 1995), which stimulates food intake and decreases thermogenesis (Zarjevski et al. 1993).

In addition to its role in promoting storage in peripheral tissues, insulin is proposed to act as an adiposity signal to the central nervous system. Research suggests that the main site for brain detection of the insulin adiposity signal, as with leptin, is within the hypothalamus, as studies have shown that insulin receptors are present, particularly in the arcuate nucleus, which plays a major role in controlling food intake and energy homeostasis (Corp et al. 1996; Baskin et al. 1999a). Insulin, like leptin, has been shown to inhibit arcuate nucleus neuropeptide $\mathrm{Y}$ expression and 
neuropeptide Y stimulation of food intake (Schwartz et al. 1992, 1993). While leptin and insulin appear to regulate energy balance under experimental conditions, their role in normal energy balance regulation in human subjects is under debate, as it is clear from epidemiological studies that levels of obesity are rapidly rising. In most individuals leptin and insulin concentrations increase in concert with rising adiposity and without indication of a direct feedback inhibition through energy balance. These findings serve to highlight the complex nature of energy balance regulation and the likely polygenic background to susceptibility to weight gain.

\section{Interaction between adiposity signals and within-meal satiety signals}

If leptin and/or insulin do influence energy balance, they need to act to directly influence short-term regulation of food intake. Recent studies have demonstrated that these 'long-term' regulators can interact with physiological factors influencing short-term meal-to-meal mechanisms associated with feeding behaviour. Intracerebroventricular infusion of insulin enhances the satiety response to CCK in rats (Reidy et al. 1995) and primates (Figlewicz et al. 1995). Intracerebroventricular injection of leptin has a similar effect on CCK satiety. Intraperitoneal injection of CCK and intracerebroventricular administration of leptin together produced a greater loss of body weight in rats than leptin alone, suggesting that $\mathrm{CCK}$ and leptin may act together to regulate body weight (Matson \& Ritter, 1999; Matson et al. 2000). Studies indicate that the enhanced reduction in body weight produced by the combination of CCK with insulin and leptin is produced by a decrease in meal size, and suggest that this response involves an interaction between forebrain responses to adiposity signals and hindbrain areas that control satiety (Reidy et al. 1995; Matson et al. 1997; Matson \& Ritter, 1999; Schwartz et al. 2000). It is proposed that the arcuate nucleus of the hypothalamus conducts adiposity signals to the paraventricular nucleus of the hypothalamus and the lateral hypothalamus, which then communicate via central autonomic pathways that project to the nucleus of the solitary tract and dorsomotor nucleus of the vagus in the brainstem. These adiposity-signalling pathways are hypothesised to integrate signals that control long-term body weight with meal-related signals that influence meal termination, resulting in regulation of meal size and cumulative food intake (Baskin et al. 1999b). As yet, data to support this hypothesis in human subjects have not been reported.

\section{Advances in the measurement of feeding behaviour}

Measurement of eating pattern within a meal has been used to determine factors associated with regulation of intake in rodents for many years (Davis, 1989). Kissileff (Kissileff et al. 1980) pioneered the use of the eatometer in human subjects to measure the microstructure of human feeding using a disguised balance on which food to be eaten would rest. Microstructural analysis of feeding behaviour has several advantages over simple measurement of food intake. Different parts of the eating of a meal have been demon- strated to be influenced by different physiological processes. For example, the early rate of eating of food is influenced by the palatability of the meal, while the decline in eating is influenced more by the energy density (and hence presumably the extent of physiological feedback stimulated; Yeomans, 1998).

As mentioned earlier, combining techniques to investigate the interactions between systems regulating intake is providing new and important information about the normal hierarchy of control of feeding. We have begun to investigate the competing influences on human feeding by combination of direct gastrointestinal preloading at different levels of energy density with measurement of eating behaviour of foods varying in palatability using a microstructural model (for details, see Yeomans, 1998). Increasing the palatability of a simple test food such as pasta and tomato sauce by the addition of herbs and salt (which has no effect on the energy density of the meal) leads to an increase in the amount of food consumed. Using the microstructural methods described earlier, it can be seen that hunger early in the test meal increases once the palatable meal is tasted, this response has been termed the appetiser effect. Now we can begin to investigate the competing influences of positive drives to eat through manipulation of the palatability of the test food with the satiating effects of preloading with direct gastric infusion of nutrients. When these comparisons are made, preloading reduces intake to a greater extent when subjects ingest a bland test meal compared with a palatable test meal (Robinson et al. 2001; Yeomans et al. 2001) suggesting that palatable meals may override partially the normal satiety process.

\section{Future perspectives}

Advances in techniques will continue to drive the understanding of the mechanisms associated with feeding, particularly new techniques allowing measurement of physiological variables in human subjects. Recent examples include the use of NMR spectroscopy in the measurement of nutrient metabolism in specific target organs (Shulman \& Rothman, 2001). ${ }^{13} \mathrm{C}$ NMR spectroscopy allows the measurement of concentrations of metabolites in specific organs and through metabolic pathways in vivo. Background levels of natural $\left[{ }^{13} \mathrm{C}\right]$ glucose allow measurement of concentrations within organs to be determined, while enriched sources allow fluxes to be measured. This procedure, in combination with stable isotopic measurement of nutrient partitioning, will allow clearer understanding of the role of postprandial nutrient metabolism in the regulation of human feeding.

Similarly, the refined technique of adipose tissue cannulation, allowing the measurement of adipose tissue deposition and/or liberation of triacylglycerol, can be used to increase our understanding of the metabolic correlates of feeding in human subjects. This technique utilises the cannulation of the vasculature draining the abdominal adipose tissue in concert with arterialised peripheral blood sampling to give arterio-venous differences in triacylglycerol and lipid fractions (Frayn et al. 1993). Utilising such techniques would benefit the understanding of the relationship between the fate of ingested nutrients and feeding behaviour. Recently, increased fatty acid incorporation into subcutaneous adipose 
tissue has been demonstrated in obese $v$. lean subjects following ingestion of a mixed meal (Kalant et al. 2000); the influence of this outcome on hepatic metabolism and subsequent appetite responses would be an interesting area for investigation.

It is increasingly clear that the physical form of ingested fats can influence the feeding response. The extent of unsaturation (French et al. 2000; Lawton et al. 2000) can markedly affect the satiating response. Similarly, chain length can also affect physiological mechanisms associated with satiety (McLaughlin et al. 1999). It is now possible to source or manufacture fats with specific fatty acid profiles, and therefore these types of manipulation may provide a method for influencing dietary-induced satiety. Caution is required, however, as studies of this type have not been extended to determine whether energy balance can be influenced over the longer term.

\section{Summary}

Our understanding of the physiological factors influencing human feeding behaviour has advanced rapidly in recent years. We now understand a great deal about the individual roles of organ systems, neurochemical signalling, metabolic regulators and psychological factors in the regulation of feeding. The challenge now is to understand how these regulators interact to influence normal feeding patterns. It is clear from the difficulties posed by drug treatments for obesity that influencing single mechanisms is rarely an ideal solution, particularly in the long term. Hence, a better understanding of the interplay of physiological factors regulating feeding will increase the chances of success in combating this global disease in a multi-factorial way.

\section{References}

Anand BK \& Brobeck JR (1951) Hypothalamic control of food intake in rats and cats. Yale Journal of Biological Medicine 24, 123-140.

Andrews JM, Rayner CK, Doran S, Hebbard GS \& Horowitz M (1998) Physiological changes in blood glucose affect appetite and pyloric motility during intraduodenal lipid infusion. American Journal of Physiology 275, G797-G804.

Baskin DG, Breininger JF, Bonigut S \& Miller MA (1999a) Leptin binding in the arcuate nucleus is increased during fasting. Brain Research 828, 154-158.

Baskin DG, Figlewicz DP, Latterman D, Seeley RJ, Woods SC, Porte D Jr \& Schwartz MC (1999b) Insulin and leptin: dual adiposity signals to the brain for the regulation of food intake and body weight. Brain Research 848, 114-123.

Beck B (2000) Neuropeptides and obesity. Nutrition 16, 916-923.

Campfield LA \& Smith FJ (1986) Functional coupling between transient declines in blood glucose and feeding behavior: temporal relationships. Brain Research Bulletin 17, 427-433.

Campfield LA, Smith FJ, Rosenbaum M \& Hirsch J (1996) Human eating: evidence for a physiological basis using a modified paradigm. Neuroscience and Biobehavioural Reviews 20, 133-137.

Castiglione KE, Read NW \& French SJ (1998) Food intake responses to upper gastrointestinal lipid infusions in humans. Physiology and Behavior 64, 141-145.
Castiglione KE, Read NW \& French SJ (2002) Adaptation to highfat diet accelerates emptying of fat but not carbohydrate test meals in humans. American Journal of Physiology 282, R366-R371.

Corp ES, Conze DB, Smith F \& Campfield LA (1996) Regional localization of specific $\{\mathrm{I}-125\}$ leptin binding sites in the rat forebrain. Brain Research 789, 40-47.

Covasa M \& Ritter RC (1998) Rats maintained on high-fat diets exhibit reduced satiety in response to $\mathrm{CCK}$ and bombesin. Peptides 19, 1407-1415.

Covasa M. \& Ritter RC (1999) Reduced sensitivity to the satiation effect of intestinal oleate in rats adapted to a high fat diet. American Journal of Physiology 277, R279-R285.

Covasa M \& Ritter RC (2000) Adaptation to a high-fat diet reduces inhibition of gastric emptying by CCK and intestinal oleate. American Journal of Physiology 278, R166-R170.

Cunningham K, Daly J, Horowitz M \& Read NW (1991) Gastrointestinal adaptation to diets of differing fat composition in human volunteers. Gut 32, 483-486.

Davis JD (1989) The microstructure of ingestive behavior. Annals of the New York Academy of Sciences 575, 106-119.

de Castro JM (2000) Eating behavior: lessons from the real world of humans. Nutrition 16, 800-813.

Degen L, Matzinger D, Drewe J \& Beglinger C (2001) The effect of cholecystokinin in controlling appetite and food intake in humans. Peptides 22, 1265-1269.

Eaton S (2002) Control of mitochondrial $\beta$-oxidation flux. Progress in Lipid Research 41, 197-239.

Farooqi IS, Jebb SA, Langmack G, Lawrence E, Cheetham $\mathrm{CH}$, Prentice AM, Hughes IA, McCamish MA \& O'Rahilly S (1999) Effects of recombinant leptin therapy in a child with congenital leptin deficiency. New England Journal of Medicine 341, 913-915.

Feinle C, Grundy D \& Read NW (1997) Effects of duodenal nutrients on sensory and motor responses of the human stomach to distension. American Journal of Physiology 273, G721-G726.

Figlewicz DP, Sipols AJ, Seeley RJ, Chavez M, Woods SC \& Porte D Jr (1995) Intraventricular insulin enhances the meal-suppressive efficacy of intraventricular cholecystokinin octapeptide in the baboon. Behavioral Neuroscience 109, 565-569.

Francis J, Castiglione KE \& French SJ (1997) Techniques for gastric distension in humans. In Ingestive Behavior Protocols, pp. 87-92 [PJ Wellman and B Hoebel, editors]. New York: SSIB.

Frayn KN, Coppack SW \& Humphreys SM (1993) Subcutaneous adipose tissue metabolism studied by local catheterization. International Journal of Obesity 17, Suppl. 3, S18-S21.

Friedman MI (1997) An energy sensor for control of energy intake. Proceedings of the Nutrition Society 56, 41-50.

French SJ, Castiglione KE \& Francis J (1997) Techniques for intestinal nutrient infusion in humans. In Ingestive Behaviour Protocols, pp. 81-86. [PJ Wellman and B Hoebel, editors]. New York: SSIB.

French SJ, Conlon CA, Mutuma ST, Arnold M, Read NW, Meijer G \& Francis J (2000) The effects of intestinal infusion of long-chain fatty acids on food intake in humans. Gastroenterology 119, 943-948.

French SJ. Murray B, Rumsey RDE, Fadzlin R \& Read NW (1995) Adaptation to high-fat diets: effects on eating behaviour and plasma cholecystokinin. British Journal of Nutrition 73, 179-189.

Geliebter A (1988) Gastric distension and gastric capacity in relation to food intake in humans. Physiology and Behavior 44, 665-668.

Geliebter A \& Hashim SA (2001) Gastric capacity in normal, obese, and bulimic women. Physiology and Behavior 74, 743-746. 
Geliebter A, Melton PM, Gage D, McCray RS \& Hashim SA (1992) Gastric capacity, gastric emptying, and test meal intake in normal and bulimic women. American Journal of Clinical Nutrition 56, 656-661.

Geliebter A, Schachter S, Lohmann-Walter C, Feldman H \& Hashim SA (1996) Reduced stomach capacity in obese subjects after dieting. American Journal of Clinical Nutrition 63, 170-173.

Granstrom L \& Backman L (1985) Stomach distension in extremely obese and in normal subjects. Acta Chirugica Scandinavica 151, 367-370.

Holst JJ (1994) Glucagon like peptide 1: a newly discovered gastrointestinal hormone. Gastroenterology 107, 1848-1855.

Jequier E \& Tappy L (1999) Regulation of body weight in humans. Physiological Reviews 79, 451-480.

Kahler A, Zimmermann M \& Langhans W (1999) Suppression of hepatic fatty acid oxidation and food intake in men. Nutrition $\mathbf{1 5}$, 819-828.

Kaiyala KJ, Woods SC \& Schartz MW (1995) New model for the regulation of energy balance and adiposity by the central nervous system. American Journal of Clinical Nutrition 62 , 1123s-1134s.

Kalant D, Phélis S, Fielding BA, Frayn KN, Cianflone K \& Sniderman AD (2000) Increased postprandial fatty acid trapping in subcutaneous adipose tissue in obese women. Journal of Lipid Research 41, 1963-1968.

Kissileff HR, Klingsberg G \& Van Itallie TB (1980) Universal eating monitor for continuous recording of solid or liquid consumption in man. American Journal of Physiology 238, R14-R22.

Kovacs EM, Westerterp-Plantenga MS, de Vries M, Brouns F \& Saris WH (2001a) Effects of 2-week ingestion of (-)-hydroxycitrate and (-)-hydroxycitrate combined with medium-chain triglycerides on satiety and food intake. Physiology and Behavior 74, 543-549.

Kovacs EM, Westerterp-Plantenga MS \& Saris WH (2001b) The effects of 2-week ingestion of (-)-hydroxycitrate and (-)hydroxycitrate combined with medium-chain triglycerides on satiety, fat oxidation, energy expenditure and body weight. International Journal of Obesity 25, 1087-1094.

Lam WF, Gielkens HAJ, de Boer SY, Lamers CBHW \& Masclee AAM (1998) Influence of hyperglycemia on the satiating effect of CCK in humans. Physiology and Behavior 65, 505-511.

Langhans W (1996) Metabolic and glucostatic control of feeding. Proceedings of the Nutrition Society 55, 497-515.

Lavin JH, Palikaridis D, Read NW \& French SJ (1997) The effect of carbohydrate utilisation during high intensity exercise on eating behaviour. Appetite 29, 402Abstr.

Lawton CL, Delargy HJ, Brockman J, Smith FC \& Blundell JE. (2000) The degree of saturation of fatty acids influences postingestive satiety. British Journal of Nutrition 83, 473-482.

Leonhardt M, Hrupka B \& Langhans W (2001) Effect of hydroxycitrate on food intake and body weight regain after a period of restrictive feeding in male rats. Physiology and Behavior 74, 191-196.

McLaughlin J, Grazia Luca M, Jones MN, D’Amato M, Dockray GJ \& Thompson DG (1999) Fatty acid chain length determines cholecystokinin secretion and effect on human gastric motility. Gastroenterology 116, 46-53.

Matson CA, Reid DF, Cannon TA \& Ritter RC (2000) Cholecystokinin and leptin act synergistically to reduce body weight. American Journal of Physiology 278, R882-R890.

Matson CA, Wiater MF, Kuijper JL \& Weigle DS (1997) Synergy between leptin and cholecystokinin (CCK) to control daily caloric intake. Peptides 18, 1275-1278.

Matson CA \& Ritter RC (1999) Long-term CCK-leptin synergy suggests a role for CCK in the regulation of body weight. American Journal of Physiology 276, R1038-R1045.
Mattes RD \& Bormann L (2000) Effects of (-)-hydroxycitric acid on appetitive variables. Physiology and Behavior 71, 87-94.

Melanson KJ, Westerterp-Plantenga MS, Saris WHM, Smith FJ \& Campfield LA (1999) Blood glucose patterns and appetite in time-blinded humans: carbohydrate versus fat. American Journal of Physiology 46, R337-R345.

Moran TH (2000) Cholecystokinin and satiety: current perspectives. Nutrition 16, 858-865.

Oster-Jorgensen E, Qvist N, Pedersen SA, Rasmussen L \& Hovendal CP (1992) The influence of induced hyperglycaemia on the characteristics of intestinal motility and bile kinetics in healthy men. Scandinavian Journal of Gastroenterology 27, $285-288$.

Plata-Salaman CR (2000) Ingestive behavior and obesity. Nutrition 16, 797-799.

Reidy CA, Chavez M, Figlewicz DP \& Woods SC (1995) Central insulin enhances sensitivity to cholecystokinin. Physiology and Behavior 58, 755-760.

Robinson TM, French SJ, Lee MD, Gray RW \& Yeomans MR (2001) Effects of test meal palatability on responses to intragastric nutrient preloads. Appetite 37, 159Abstr.

Rolls BJ, Gnizak N, Summerfelt A \& Laster LJ (1988) Food intake in dieters and nondieters after a liquid meal containing mediumchain triglycerides. American Journal of Clinical Nutrition 48, $66-71$.

Russek M (1963) An hypothesis on the participation of hepatic glucoreceptors in the control of food intake. Nature 197, 79-80.

Russek M (1970) Demonstration of the influence of an hepatic glucose-sensitive mechanism on food intake. Physiology and Behavior 5, 1207-1209.

Schvarcz E, Palmer M, Aman J \& Berne C (1995) Hypoglycemia increases the gastric emptying rate in healthy subjects. Diabetes Care 18, 674-676.

Shvarcz E, Palmer M, Aman J, Horowitz M, Stridsberg M \& Berne C (1997) Physiological hyperglycemia slows gastric emptying in normal subjects and patients with insulin-dependent diabetes mellitus. Gastroenterology 113, 60-66.

Schvarcz E, Palmer M, Aman J, Lindkvist B \& Beckman KW (1993) Hypoglycaemia increases the gastric emptying rate in patients with type 1 diabetes mellitus. Diabetic Medicine 10, 660-663.

Schwartz MW, Figlewicz DP, Baskin DG, Woods DC \& Porte D Jr (1994) Insulin and the central regulation of energy balance. Endocrine Reviews 2, 109-113.

Schwartz MW, Sipols AJ, Grubin CE \& Baskin DG (1993) Differential effect of fasting on hypothalamic expression of genes encoding neuropeptide Y, galanin, and glutamic acid decarboxylase. Brain Research Bulletin 31, 361-367.

Schwartz MW, Sipols AJ, Marks JL, Sanacora G, White JD, Scheurink A et al. (1992) Inhibition of hypothalamic neuropeptide gene expression by insulin. Endocrinology 130, 3608-3616.

Schwartz MW, Woods SC, Porte D Jr, Seeley RJ \& Baskin DG (2000) Central nervous system control of food intake. Nature 404, 661-671.

Shulman RG \& Rothman DL (2001) ${ }^{13} \mathrm{C}$ NMR of intermediary metabolism: implications for systemic physiology. Annual Review of Physiology 63, 15-48.

Smith FJ \& Campfield LA (1993) Meal initiation occurs after experimental induction of transient declines in blood glucose. American Journal of Physiology 265, R1423-R1429.

Stephens TW, Basinski M, Bristow PK, Bue-Valleskey JM, Burgett SG, Craft L et al. (1995) The role of neuropeptide Y in the anti-obesity action of the obese gene product. Nature $\mathbf{3 7 7}$, 530-532.

Stubbs RJ \& Harbron CG (1996) Covert manipulation of the ratio of medium- to long-chain triglycerides in isoenergetically dense diets: effect on food intake in ad libitum feeding men. 
International Journal of Obesity and Related Metabolic Disorders 20, 435-444.

Watson JA, Fang M \& Lowenstein JM (1969) Tricarballylate and hydroxycitrate: Substrate and inhibitors of ATP:citrate oxaloacetate lyase. Archives of Biochemistry and Biophysics 135, 209-217.

Yeomans MR (1998) Taste, palatability and the control of appetite. Proceedings of the Nutrition Society 57, 609-615.
Yeomans MR, Lee MD, Gray RW \& French SJ (2001) Effects of test-meal palatability on compensatory eating following disguised fat and carbohydrate preloads. International Journal of Obesity 25, 1215-1224.

Zarjevski N, Cusin I, Vettor R, Rohner-Jeanrenaud F \& Jenrenaud B (1993) Chronic intracerebroventricular neuropeptide-Y administration to normal rats mimics hormonal and metabolic changes of obesity. Endocrinology 133, 1753-1758. 